\title{
Article
}

\section{Twitter city and Facebook village: Teenage girls' personas and experiences influenced by choice architecture in social networking sites}

\author{
Binns, Amy \\ Available at http://clok.uclan.ac.uk/15534/ \\ Binns, Amy ORCID: 0000-0002-9173-3108 (2014) Twitter city and Facebook \\ village: Teenage girls' personas and experiences influenced by choice \\ architecture in social networking sites. Journal of Media Practice, 15 (2). pp. \\ 71-91. ISSN 1468-2753
}

It is advisable to refer to the publisher's version if you intend to cite from the work. http://dx.doi.org/10.1080/14682753.2014.960763

For more information about UCLan's research in this area go to http://www.uclan.ac.uk/researchgroups/ and search for <name of research Group>.

For information about Research generally at UCLan please go to http://www.uclan.ac.uk/research/

All outputs in CLoK are protected by Intellectual Property Rights law, including Copyright law. Copyright, IPR and Moral Rights for the works on this site are retained by the individual authors and/or other copyright owners. Terms and conditions for use of this material are defined in the policies page.

\section{CLoK}

Central Lancashire online Knowledge www.clok.uclan.ac.uk

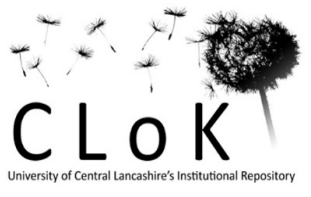


Twitter city and Facebook village: Teenage girls’ personas and experiences influenced by choice architecture in social networking sites

Author: Amy Binns

Senior lecturer, University of Central Lancashire,

Email: abinns@uclan.ac.uk 


\begin{abstract}
Anonymity was once the norm online, but uploading personal information on social networks is now ubiquitous amongst teenagers, leading to new concerns about abandonment of privacy and obsessive self-grooming of online identities. However, researchers have not examined whether different social networks result in differing behaviour or happiness, which should be a key issue for media practitioners involved in social network design.
\end{abstract}

This research examines whether different SNs affect behaviour and happiness differently by examining usage of Facebook, Twitter and Q\&A sites Formspring and Ask by 342 teenage girls. Results showed they felt more confident on Twitter than Facebook, but were more likely to agree their Facebook personas were "the real me". Fewer negative experiences were reported on Twitter. Despite Ask.fm’s appalling reputation, there was little statistical difference between it and Facebook across most categories. Though judgemental about 'fake’ behaviour, girls reported often concealing their feelings.

This article shows behaviour, influenced by site architecture, has created varying environments, through new media practices which can be characterised as "choice architecture” or "persuasive design”. In turn, these differing environments continue to influence users’ behaviour. Understanding these mechanisms could help site designers create safer online environments which promote rather than degrade users’ mental health. Persuasive design on SNS also has implications for researchers seeking to understand behaviour on these platforms and craft future studies, as well as being an important field of future study in its own right.

Keywords: social networks; social media practice; self-presentation; choice architecture; website design; adolescence Email: abinns@uclan.ac.uk 


\section{Introduction}

Sites based on user generated content have a symbiotic relationship with their users. The content the users upload or create obviously changes the site, but the site's tools and capabilities also influence the way users behave and the identities they develop within the site (McCreery et al 2013). The same process happens at an emotional level: the users' behaviour creates the "feel" of the site, but this reflects back at the users and further influences their behaviour (Kramer et al, 2014; Binns 2012). Web designers and media owners go to great lengths to court greater engagement, but are also aware that the emotional quality of this engagement is crucial, necessitating the employment of moderators and community managers. For media practioners, understanding how the design of their sites will affect users' behaviour could circumvent this difficult process by designing for positive behaviour from the outset, rather than trying to edit or control negative behaviour when the site is live and busy. Designing to promote mental health may also create longer-lasting sites, social networks being notoriously short-lived. Academics across many disciplines including media practice, social science, psychology and mental health can also improve their understanding of online behaviour by considering these design issues.

From the users’ point of view, young people frequently join social networks because their offline community is migrating there - Friendster, Myspace and Bebo have all had moments - without understanding the differences they will experience between networks, and the way they and their friends will be influenced, as individuals and in terms of their intergroup relationships (Chou and Edge 2012). The West's culture of individual freedom may make young people believe they are beyond subtle influence but this is clearly not the case. A further understanding by media educators of how these influences operate could help them make more informed choices. 
This research examined how young women’s online behaviour, identities and happiness were influenced by the social networks they used. This paper goes on to discuss how their behaviour, influenced by the site architecture, has created significantly different online environments, which I have termed the Twitter City and Facebook Village. In turn, these differing environments continue to influence users' behaviour. In a sense, the site design is a type of choice architecture, as described by Sunstein and Thaler (2008). It is a way of presenting different options, which nudges users towards certain decisions and behaviours.

Although not always framed as such, these new media practice principles, sometimes called persuasive design, have been well understood commercially for several years (Sutcliffe 2001; Winn and Beck 2002; Cyr and Bonanni 2005; Kim and Fesenmajer 2008) but has only more recently been examined from a not-fot-profit perspective (Hovarth 2011; Lehto and Oinas-Kukkonen 2011). Research on choice architecture in social media is sparse. Benney (2013) evaluated Chinese social networking site (SNS) Weibo from a state-control perspective, noting how users are obliged to register one or more interests (most based on entertainment and consumerism), forcing them to follow a particular set of verified users intended "to maximise the cacophonous spectacle of entertainment and to minimise reasoned discussion and debate". These features compare to the less rigid Twitter "Who to Follow" and "Popular Accounts".

Marichal (2012) has written that Facebook created an "architecture of disclosure”; Fogg and Iizawa have compared the "assertive and mechanistic" design of Facebook with the “subtle and indirect” design of Japanese SNS Mixi. They particularly study methods of inviting friends (usually friends of friends, or email contacts, ie, individuals' direct offline contacts). However, no studies I am aware of compare different sites intended for the same audience. 
I am unaware of any research (except my own, Binns 2013) on Formspring.me and Ask.fm, which are Q\&A sites allowing anonymous questioning by people who know each other offline, and which have been associated with extreme abusive behaviour and several teenage suicides (Author, 2013). As the creators of Ask describe it as a 'clone' of Formspring, these sites are being treated as identical (O’Hear 2012). These sites could be characterised as inward-looking SNS, particularly as they are usually activated with a Facebook log-in allowing users’ Facebook friends to be immediately imported as contacts.

Many researchers have focussed on links between SNS use and young people's relationships and wellbeing (Livingstone 2008). However, most studies have examined the differences between young people who use SNS and those who do not, or who use SNS more or less heavily (Chou and Edge 2012). Hughes (2012) examined site users’ personality differences, but no research has looked at the differences in outcomes from different sites.

\section{RQ1: How do levels of positive and negative experiences vary between Facebook,}

\section{Twitter, Formspring and Ask.fm sites and how do the girls feel about it?}

It has long been observed that the experience of being online results in a change of behaviour (Suler 2004). Young people are, more than ever, acutely aware of their SN profiles as their own "shop windows", sometimes called "Brand You”, with the best possible display being crucial for social success (Livingstone 2008, Waters and Ackerman 2011). Selfpresentation is a major part of SNS use, and is also a major concern for many adolescent girls.

Site architecture is in itself a type of choice architecture which may produce different results in terms of self-presentation and behaviour, with some users deliberately choosing to create an "idealised” version of themselves according to current cultural norms. For media practioners, understanding these behavioural drivers can help with design of sites that makes 
self-presentation manageable. As I am concerned here about girls' wellbeing, I focus here on reported self-presentation and behaviour, partly building on categories defined by Valkenburg (2005).

\section{RQ2: How do girls perceive their self-presentation varies between Facebook,}

\section{Twitter, Formspring and Ask, and how do they feel about this?}

Some social commentators judge young people harshly for the apparently frivolous or superficial personalities they "reveal" on these sites, on the assumption that the online identity is the "real" person, and the identity they exhibit to their family, teachers or employers is a construct, possibly intended to deceive. Many researchers have been concerned at the apparent disregard for privacy shown, and the difficulties of maintaining privacy (Wessels 2012). I posit that these profiles, though intended to appear open and honest to their peers, may actually hide as much as they reveal.

\section{RQ3: What do girls conceal when online, and how do they feel about this?}

Throughout this research I have been concerned to allow these girls' to be heard, rather than using a purely quantitative analysis which may be reductive. Therefore the research questions above all end "and how do they feel about it?”, which will be answered in the girls' own words throughout the results section, although I acknowledge these comments are at times contradictory or even nebulous. All spelling and grammar is uncorrected.

\section{Research methods}

Research design in this area is difficult, perhaps accounting for the paucity of studies as mentioned above. One large-scale experiment by Facebook attracted widespread criticism of unethical practices due to lack of consent (Waldman 2014), while studies that seek to use 
textual analysis tools such as the Linguistic Inquiry and Wordcount Software also suffer from the problem that these tools were designed for analysis of lengthy documents and do not take account of sarcasm which forms a huge proportion of SNS content (Matthews 2014). As Aiken and McMahon said (2014), traditional research methodology is "beginning to look quaint”.

Consequently, this study did not seek to analyse or manipulate girls’ actual pages, but instead relies on self-reporting. The survey about representation of the self in social networks was drawn up following a focus group at a British state girls' school to ensure clear language was used and appropriate issues covered. In order to prevent contamination by students’ contact with the researcher, the survey was then released in three different British state girls' schools in Years 9, 10 and 11, (totals: aged $13=81$, aged $14=116$, aged $15=123$, aged $16=$ 22). Parents were given the opportunity to opt their children out of the survey. The remaining children were given access through the schools' intranet sites, along with information sheets, including anti-bullying helpline numbers and websites. For ethical reasons, the survey was not compulsory or done in class. Girls’ schools were used because self-presentation is particularly important to teenage girls, though boys are becoming more image-conscious (Simmons 2011).

Quantitative and qualitative analysis were used through a mixed methods approach (Wimmer and Dominick 2011, 121), with Likert-type scales for the girls' feelings about their experiences on different platforms and multiple-choice questions about self-presentation. This Likert-type scale is an ordinal scale, which is a rank test providing ordinal data. The results for specific experiences for girls who had used all platforms were subjected to Freidman's rank test. Where necessary, post-hoc analysis of Freidman's rank test was carried out using the Wilcoxon signed-rank test with Bonferroni adjustment to avoid Type 1 errors. 
Skip logic was used if respondents did not use a particular platform. An open question was asked to enable their voices to be heard (Fairbrother 2007), “Is there anything else you'd like to say about how it feels to be online?” which was subject to discourse analysis. They were also asked to provide alternatives to the terms "real/virtual".

\section{Results}

In total, 342 girls took the survey. Of these, Facebook-users n=279, Twitter-users $n=188$, Ask/Formspring-users $n=146$, using all three sites $n=112$ (further usage statistics in Appendix 3). No question was compulsory so response numbers for individual questions vary slightly. These numbers are given for interpretation of the results, and are unlikely to be representative more generally. In some schools, social groups may migrate en masse to a particular network which pupils at a nearby school may not use at all. Usage is also fast changing.

\section{RQ1: How do levels of positive and negative experiences vary between popular social} networking sites?

Girls were asked “How would you describe your experiences on [name of platform]?” Eight characteristics, four positive and four negative, were presented in randomised order, with students responding on a five point Likert-type scale where $1=$ strongly disagree and 5 $=$ strongly agree. Full results are given in Appendix 1.

In order to produce a quantitative analysis of this ordinal data, the results for girls who used all sites ( $\mathrm{n}=112)$ were then subject to paired analysis through Freidman's Rank Test. Some girls did not answer every question, so numbers in column 2 of Table 1 (showing 
negative experiences) and 3 (positive experiences) vary slightly. The tables shows significant differences across the sites for all experiences. Post hoc analysis was used to narrow down where the differences between sites lie. Tables 2 and 4 shows the results.

These show that respondents feel Twitter is less frightening, less embarrassing and less upsetting then the other two sites. The mean ranks (shown in Table 1) support this result with the value for Twitter being relatively much lower than those of Facebook and Formspring/Ask. (Note that with Table 1 the higher the mean rank, the more negative the experience). With all three of these factors however, there is no significant difference between Facebook and Formspring/Ask, an interesting result given Formspring/Ask’s appalling reputation and the multiple suicides reported in the media associated with usage of these question and answer sites.

In relation to respondents 'feeling left out', Facebook stands out. Here the mean rank supports the finding that respondents are significantly more likely to 'feel left out' using Facebook compared to the other sites. By contrast there is no significant difference between Formspring and Twitter.

Facebook’s algorithms drive more “popular” stories up news feeds, which can make it appear that everyone else is having a more interesting time, and being rewarded with more comments and likes. These results agree with several other studies that have shown this can cause depression or “fear of missing out” (Chou and Edge, 2013; O’Keeffe and ClarkePearson, 2011). These results suggest that it also causes embarrassment.

Sharing photographs taken on nights out is a common Facebook practice, which can cause problems. One girl wrote: 
Overall, it's really good like Twitter and Tumblr and there are never any problems. But Facebook is more embarrassing (but only because there are usually really bad pictures of you or something like that).

The girls also seemed conscious of Facebook’s potential for misunderstandings, the difficulties of mis-reading and being mis-read was a common theme in comments . Examples include:

Sometimes it feels a little clinical, a bit black or white. Also I can feel quite frustrated after being on facebook for a while and very bored with other peopl being very harsh and using it to hurt others feelings.

I think that a lot of people use the internet to say things that in reality wouldn't be said in real life which leads to people becoming upset as comments are often hurtful.

When online, you don't get emotions than you do in person, so something might seem to be mean but it was meant to be sarcastic

Although Facebook has famously refused to install a "dislike” button, the focus group commented that sometimes, several people will "like" a mean remark. Although these people are unlikely to feel much responsibility (for they haven’t actually made any unpleasant remark themselves), the overall effect is of making the target feel "ganged up on".

Formspring and Ask, where users may take advantage of anonymity to send abuse, delivers more upsetting, embarrassing and frightening experiences than Twitter. One girl wrote: “its really good on twitter but ask fm and formspring are made for bullying”.

When asked about positive experiences, Formspring/Ask trails in third place in every category. Freidman's rank tests find that there are statistically significant differences across all of the positive experiences in relation to the social networking sites. However, although Freidman's test can show that there significant differences in between the social networking sites and the respondents’ positive experiences, it cannot show where those differences lie. Therefore post-hoc analysis via pairwise comparisons, was again carried out, in order to show where the significant differences between sites are. Table 4 shows the results. 
Post hoc analysis shows that for the experiences "Fun", "Friendly", and "Confidence Building", the results for Formspring/Ask are significantly different to those of the other two sites. This is supported by the mean ranks for each social networking site shown in Table 3 (Note that within this table the higher the mean rank, the more positive the experience). Here Formspring/Ask has a much lower mean rank than either Facebook or Twitter suggesting a less positive experience. By contrast Facebook and Twitter show no significant differences across these three experiences.

For "Interesting" it is Twitter that is significantly different to the other sites. Again the mean rank supports this, showing a much higher relative value than Facebook or Formspring/Ask. There is however no significant difference between Facebook and Formspring/Ask.

Hughes (2012) has shown personality differences between Facebook users and Twitter users, so it could be considered that this could account for part of these results, however, Hughes recruited Twitter users and Facebook users, his research did not set out to compare experiences for those who had tried both platforms. This research partly challenges his results, and could show that site architecture was creating different experiences.

RQ1 result

Twitter provides fewer negative experiences than Facebook in every category measured, and is more interesting than any other site. Girls are more likely to feel left out on Facebook than any other site. Formspring/Ask provide fewer positive experiences than Twitter or Facebook, and similar levels of negative experiences as Facebook. 


\section{RQ2: How do girls feel their self-presentation varies between popular SNS?}

Girls were asked “On [name of platform], are you (tick as many as apply)...” for Facebook, Twitter and Ask/Formspring. They were also asked the same question for a final section about who they were across all the sites they contributed to, described as "the online you”.

Chart 1: Changes in persona by platform, by percentage response. Facebook n=279, Twitter $n=188$, Ask/Formspring n=146, all platforms n=342.

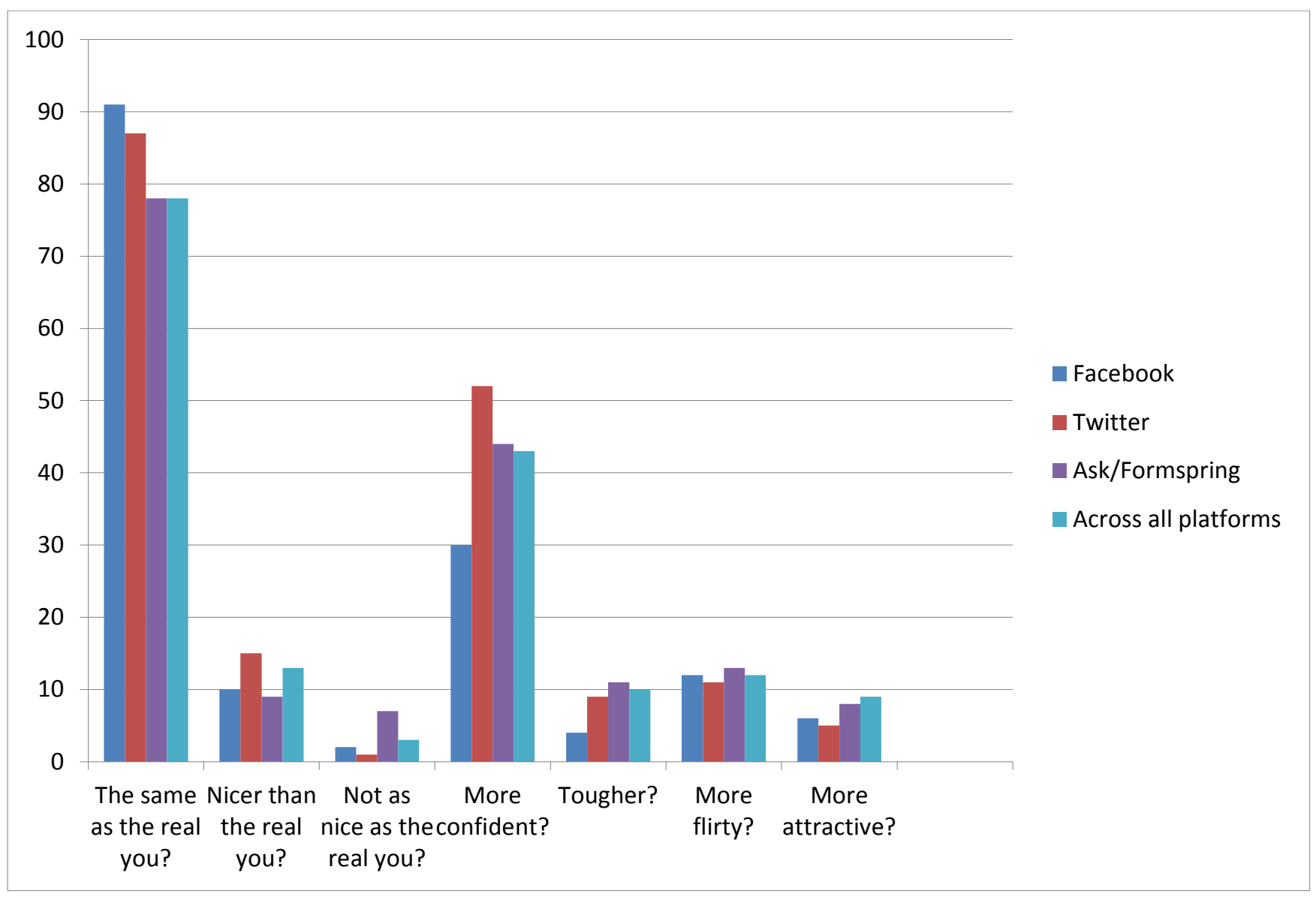

The same yet different

The first significant result was that most respondents ticked "the same as the real you" plus at least one other option, which at first seems contradictory. To consider three possible 
explanations: firstly, it may be that the subjects did not understand the question properly: the concept of a "true self" is debatable and the girls may be confused about what they were being asked to consider. Secondly, their responses may be strictly accurate - they consider they are "the same as the real you” but are showing more prominently a facet of their personality. Thirdly, it may be they are unwilling to admit their online selves are different.

To explore this final possibility, the concept of behaving differently online may be seen as deceptive. The girls were asked to provide alternative pairs of words for "real/virtual": 179 answered the question, but there was no consensus as to whether real and virtual were the right words. Of these, 66 provided other pairs or phrases, of which 27 were value-laden responses such as "honest and fake”, “true or false”, “honest fantasy”. Some suggested words along the lines of “you/you acting different” "you/not you”. They are obviously conscious the online world is significantly different and are making a strong value judgement. They may be more judgemental about what is perceived as "fake” behaviour online than older people.

This may explain why they are largely clicking on "the same as the real you". In their view, anything else is dishonest. These results seem to imply the girls are unwilling to fully admit, even in this anonymous survey, that their online selves are different. However, nonetheless most girls felt they were different online, with results varying from one platform to another.

\section{Increased confidence}


The most common change in persona was that online, the girls were more confident. This is likely to be a strong reason for the attractiveness of these sites for this age group. This emerged strongly as a theme in comments given by the respondents:

you feel almost invincible, as if what you say or do won't ever come back to haunt you or won't effect anyone else. because people can't see your face, you pretty much say hwat you want and feel ,and are more confident. But this applies to all non face-to-face communication. MORE CONFIDENT I CAN PRESENT AN IMAGE OF MYSELF THAT I REALLY LIKE AND WANT OTHER PEOPLE TO THINK

It makes me feel more confident as i can think about what i am going to type

it feels like you cant fail or do something wrong

everyone online, whether they realise it or not, is being an exaggerated + more confident version of themselves. half of the things that anyone posts online is just an over the top version of what they really want to say.

An anomaly is that, as described above in RQ1, students said that they generally didn't find Formspring confidence building compared to the other platforms, but did say they were more confident on Ask/Formspring than Facebook in Chart 3. I would conclude that the Ask/Formspring “confidence” is borne from the opportunity to hide in anonymity when desired, but the girls themselves recognise it is not a lasting positive effect on character or happiness as implied by “confidence-building”.

The results also showed a difference between platforms, with Twitter creating substantially higher confidence levels. One surprise was how low Facebook falls, with significantly lower levels of confidence than being online generally. Although $30 \%$ of respondents said their Facebook personas were more confident than the "real" them, this was lower than for other platforms, which were between 43 and 52 per cent. "Less confident” was not offered as an option; this may have produced interesting results. 
This spread was inverted for the category "the same as the real you”, where $91 \%$ of respondents felt their Facebook persona was an accurate reflection of themselves, with lower results for other platforms. Zuckerberg famously said that people who wanted more than one identity lacked integrity (Kirkpatrick 2010). It seems he has achieved what he wanted beyond mere biographical information: it does seem more difficult to even tweak your identity on Facebook than on other platforms. For adolescent girls who are deeply concerned with selfpresentation strategies, this may not be a positive. This restriction of the ability to experiment with your identity may partly explain the results in Charts 1 and 2, showing Facebook produces more negative and fewer positive experiences.

Girls were more likely to say they were nicer on Twitter than Facebook, and less likely to say they were not as nice; they were more likely to say they were not as nice on Formspring/Ask.

In comments, 12 girls said they were funnier or wittier. Perhaps this should be considered as a category in future studies. Four said they were sexier or hotter ("hotter than the sun x"), possibly the phrase “more attractive” did not resonate.

\section{Comparison with Valkenburg}

The final three categories are based on those used in Valkenburg et al's landmark study on adolescents' identity experiments on the internet, in which young people were questioned about their behaviour when pretending to be someone else online. I replaced her “more macho” with “tougher” as being more appropriate for a female group (Valkenburg’s other categories - opposite gender, real-life acquaintance, elaborated fantasy person and other - were not included as being inappropriate for platforms that are based on offline identities). 
In this study young people are enhancing their online presentation of their offline identity, but the changes they make are comparable. The "more beautiful/attractive” category (7.5 per cent across all platforms) and “more flirtatious” category (12.9 per cent across all platforms) are similar to Valkenburg's results. Valkenburg found only 2.9 per cent described themselves as more macho, but my results show the "tougher" category is higher at between nine and 11 per cent, except for Facebook, when it is only four per cent, a reduction that mirrors the "more confident” category. Her highest result was for teenagers pretending to be older (49.8 per cent), the “more confident” result in this survey may mirror this.

RQ2 result

Self-presentation varies significantly between platforms. Twitter produces higher levels of confidence than any other platform, with 52 per cent of girls saying they are more confident on Twitter. Facebook produces lower levels of confidence than any other platform, although 30 per cent of girls still felt more confident on this network than offline.

\section{RQ3: What do girls conceal when online?}

After sections about different platforms, the following question was asked: "This is the last set of questions. It's about who you are across all the sites you use. It's NOT about what other people might write about you, or the pictures other people might tag you in. If you added up all the status updates, comments, pictures, videos and likes you've put ANYWHERE online, including Facebook, twitter, Formspring, Ask.fm, Youtube and anywhere else, would it add up to the REAL you?” 
In reply ( $\mathrm{R}=321), 33$ per cent clicked "It would totally add up to the real me”, 61 per cent clicked "It would mostly add up to the real me", 4 per cent clicked "It would mostly not add up to the real me” and less than 2 per cent (five respondents) clicked "It wouldn't be the real me at all”.

On the next page, the girls were asked: "If it wouldn't totally add up to the real you, which bits of the real you are missing? Tick as many as apply.” This was only visible after the question above had been answered (or skipped). Skip logic was not used to filter out those who had said "It would totally add up to the real me", to give these girls a chance to consider again when offered more possibilities. However, all subjects who clicked the "totally" option, chose to skip it. In fact, this question was one of the most skipped of the tick box questions (as opposed to comment boxes), with only 164 choosing to answer it, though all respondents saw it. Perhaps the options did not resonate. In order of magnitude, 62.2 per cent said they concealed their hopes and fears, 60.4 per cent concealed their real feelings about themselves, 54.3 per cent concealed their ambitions, 45.1 per cent concealed their real feelings about their families and 34.8 per cent concealed their real feelings about their friends.

For the same question, 45 girls ticked the “other” box and provided comments, six put "none" or "N/A", four said they did not understand the question. The most common response (15) was that they were generally more private, with comments such as: “I don’t feel the need to tell the internet everything about me. I don’t lie but I don’t say anything people don’t need to know", "anything deep or anything more than trivial” and "personal details, most of my statuses are song lyrics or events with friends I think.”

The significant levels of missing information lends even more weight to the view that online selves represent no more than personas developed for certain purposes. Although the girls may consider their online selves are "the same as the real you”, they still represent a 
severely edited version. Durrant et al (2011) used teenagers’ photographic displays at home and online to demonstrate the divide between the two as part of a transitioning process from childhood to adulthood. Although they described themselves as very much connected to their homes and families, she showed how cut off their families were from their lives outside the home. The above table seems to show the reverse is also true: the friends who are the audience for the online persona are also cut off from the creator's inner and family life. Comments made included:

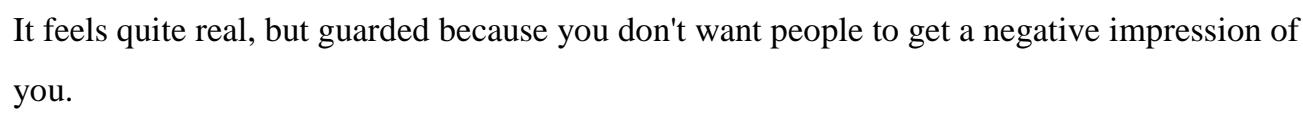

We can see here that some girls are concerned not just about managing their selfpresentation, but also being judged for managing their self-presentation (being 'fake' or 'twofaced'), and even, in the last comment, burdening others with their emotions.

RQ3 result

Respondents are actively editing their online selves for various reasons. They are most likely to conceal their true feelings about themselves, their hopes and fears, but may also conceal their ambitions, and feelings about their families. They are least likely to conceal 
their feelings about their friends, although a third admit to this. In contrast to popular belief, privacy is clearly a concern for this age group.

\section{Discussion}

In the early days of Web 2.0, researchers found that increased time spent online, usually in multiplayer games or forums, resulted in worsening offline relationships and wellbeing for adolescents , this was a source of great anxiety for all those responsible for young people. However, as the numbers online increased, young people using the internet to communicate were largely doing so with their offline peer group through social networking sites (SNS), and Valkenburg (2009) reported that this increased self-disclosure improved their relationships and wellbeing, in contrast to those young people who spent their time online communicating with strangers.

By 2012, a systematic review by Nguyen of research on online versus offline selfdisclosure found much less clear-cut results. Recent research has also found that teenagers increasingly dislike the "drama” of Facebook and see it as a social burden (Pew 2013; Reich 2010), and that the increasing numbers of parents present also affect their enjoyment (Pew 2013). This was voiced by the survey respondent who wrote:

i hate having the internet. it would be nice to go home from a day of bitching, and being able to escape from everything instead of having to go online. because your friends want to talk to you and would get annoyed at you if you didn't reply in time or ignored them for a while.

The RQ1 result confirms this, Facebook and Formspring/Ask, both platforms which encourage engagement with offline contacts, are producing more negative experiences than Twitter. Have we now reached a point where mass use of social networks, combined with 
choice architecture designed to increase engagement, has made us hyper-connected in a way that has become stifling?

Baumgartner (1991) described how affluent youngsters growing up in the West have largely lived offline under "moral minimalism”, where the peace and quiet of the suburbs is the result of weak ties, independence amongst people, social fluidity and mobility, individuation and social fragmentation. Tensions and conflicts are dealt with through avoidance, tolerance and silent exclusion.

As RQ1 shows, an inward focussed SNS such as Facebook or Formspring/Ask renders these solutions to conflict impossible. Anyone excluded is fully aware of it when pictures of the parties they weren't invited to are uploaded, avoidance and tolerance are far more difficult when users are daily or even hourly confronted with others’ views, and see instant gangs forming through people using the "like" button to vote on controversial comments. The pressure to take sides in a row may be irresistible.

The Facebook experience as it stands now could be compared with the experience of village life, which young people have also found claustrophobic and controlling. Formspring/Ask, with its anonymity facilitating ridicule and judgemental behaviour, also magnifies conflict. Although traditionally idealised in Britain, other cultures have recognised village life, where everyone knows everyone and everything, as limiting freedom due to judgemental gossip and the insistence on social norms.

Haugen and Villa’s study showed how young people in rural Norway, though valuing the security of their close-knit communities, also faced gossip, exclusion and ridicule if they deviated from strict social norms. They said: "The fear of being talked about functions as a limitation to individual freedom. In other words, the imagined informal social control becomes real in its consequences.” $(2006,215)$ 
Glendinning et al found similar feelings of constraint in a survey of rural young people across three European countries. They said:

Those young people who felt that rural life was like 'living in a gold-fish bowl' and that 'visibility’was a major issue ... were more likely to report lower self-esteem, depressed mood, affective symptoms, and also, poorer self-rated health... Additionally, and importantly, the linkage between rural life perceived as constraining and self-esteem was significantly more marked among young women. $(2003,145)$

This is echoed in my survey by the girl who wrote:

I feel more confident on Twitter because barely any of my friends follow me - it's lots of other people who I dont know so I can say what I really think without people that I know judging me. When I'm on Facebook I never put statuses because it's too personal and judgemental.

In a sense, Facebook has brought village life to the masses. Designed for the hothouse, supercharged village of campus life, it can result in a closed, socially homogenous circle producing narrow interests and narrow minds. This has the effect of magnifying tiny differences and incidents.

Twitter has been designed differently. It is perfectly acceptable to follow people you don't know, with celebrities and other elite users banging their drums for attention and garnering millions of followers. It is also acceptable to produce little content. Of $637 \mathrm{~m}$ profiles, only $272 \mathrm{~m}$ accounts have ever tweeted at all , and only $80 \mathrm{~m}$ accounts have tweeted in the past month. Of these $80 \mathrm{~m}$ active users, the median number of followers is a mere 31 (the average is 235, artificially inflated by the elite users such as Justin Bieber's 40million followers) (Basch, 2012). Compared to the average Facebook user's 130 friends, this is very low, but this in itself may give freedom. Twitter "offers the opportunity to reinstate some of the anonymity previously sought online.... Users do not need to post information about themselves to find 'friends' and thus the site focuses less on 'who you are' and more on what you have to say” (Huberman et al., 2009, cited by Hughes et al, 2012). A small number of 
young Twitter users do not consider it a social network site at all (Pew 2013) and some researchers claim it could be considered as a news site (Kwak et al 2010).

These aspects can be seen in the choice architecture of the sites, nudging users towards certain types of behaviour. The relationships between site designers/managers and social networks/forums can be likened to many things: gardens and gardeners (Binns 2012), pubs and landlords, and others, but extremely large sites make direct control very difficult (Kelion, 2013) and the choice architecture of the site becomes the only significant means of influence.

Facebook, Twitter and Formspring/Ask can all be used as social networking sites by groups of people who know each other offline, but the site design influences the result. Formspring and Ask's USP, the ease of anonymity, results in a prurient but sometimes hostile environment, both sites have been linked to several teenage suicides (Binns, 2013).

Meanwhile, Twitter nudges people towards a more outward looking experience. The Trends feature is drawn from across the world or a specific country, depending on your settings, and will include subjects your friends are not necessarily talking about. Clicking on it will show you comments from people you don’t know. Retweeting their comments and following them will be considered flattering by the authors. The site design thus encourages contact with strangers. The Who to Follow box will include people who are friends of friends in a way similar to Facebook’s “Do you know..” feature, and suggestions of groups to follow, but it also includes Popular Accounts, which links to a list of categories similar to any large media company: Music, Television, News, Entertainment, Sport, Technology, Government and Business to list the top few. The accounts in each section are well known people and influential organisations. 
As a result, people also treat it as a news feed. Although previous studies have shown that, at least on a political level, Twitter users tend to cluster into subgroups of highly selfconnected users who are usually politically homogenous (Himelboim et al, 2013), many young people say they get breaking news from Twitter (Kwak, 2010). These stories encourage people to look outwards and comment on stories from the wider world, rather than on stories generated within their own social circles.

In contrast, Facebook’s “news feed” largely shows the top ranked (ie most commented or liked) status updates from amongst the user's friends or groups, particularly from those the user has defined as close friends. The only other items in a news feed are sponsored links, or updates from pages (usually businesses or fan pages). It is this magnifying glass focus on events within a social circle which results in the drama that young people complain of on Facebook (Pew, 2013) and in this research due to asynchronous commenting and misunderstanding (Reich, 2010). The contrast between outward and inward focus is shown in the positive experiences results in RQ1: though Facebook and Twitter produce similar results for fun, friendly and confidence-building, Twitter is judged to be more interesting.

Although Twitter is obviously designed for interaction, the site architecture provides fewer obvious opportunities than Facebook to speak. There is always one tiny tweet button at the top right, the home page includes a "Compose New Tweet” box which disappears on scrolling down, and reply buttons appear when hovering over a tweet, but these are subtle compared to Facebook's repeated empty boxes inviting comments on everyone else's status updates, constantly nudging the user to interact. 
This is an example of the new media practice of choice architecture. It is more possible to have a relaxing “consumer” experience on Twitter, whilst Facebook’s endless demands for engagement may be emotionally draining.

Some young people also complain that maintaining a Facebook page is more work, and again the site architecture asks users to reveal more: their favourite music, books, and television shows, their marital status, religion, politics, hometown, the places they visit and much more. They are even invited to upload material from before Facebook existed to create a timeline of their lives. These are then clearly displayed on profile pages with picture icons. Marichal (2012) refers to this as an 'architecture of disclosure'. Failing to fill in all the categories results in empty boxes reminding you to fill in more details when you view your own profile. This provides Facebook with valuable marketing information, but also forces users concerned about self-presentation to create ever more elaborate shop-windows for "Brand You”.

Although Twitter also makes available lists of Followers, Following, Lists and Favourites, they are simply buttons which have to be clicked to reveal the information, rather than picture grids that display automatically. There is a 160 character limit for your biography.

A much retweeted quote is "Facebook is for people you went to school with. Twitter is for people you wished you went to school with” (unable to find original source). Perhaps Twitter can be compared to sitting at a cafe table in St Mark’s Square, watching the fashionistas pass by, while Facebook and Formspring/Ask are like hanging out at your local bus shelter, staffroom or parent and toddler group. If Facebook, designed with a campus mentality, represents the comforting, conformist safety of the village, Twitter may represent the liberal-minded freedoms, diversity and anonymity of the city. Having thoroughly 
explored the hypernetworks of Facebook, these young people may be willing to embrace the original internet concepts of freedom and exploration. The refreshing escape from village life is seen in the RQ2 result: girls are more confident on Twitter. Comments on this desire to escape the known included:

\section{MY ONLINE FRIENDS ARE THE BEST THING IN MY LIFE AND I DON'T KNOW WHAT I'D DO WITHOUT THEM AND THIS IS IN CAPS LOCKS BECAUSE IT IS IMPORTANT.}

People whom I've met online I feel I can relate more to and I like more than most people in 'real life'

Like belonging...my fandom loves me! and my OTP [one true pairing] completes me, I'm from Tumblr... Run away, run now.

It feels like a crazy universe too large to explore made of a hundred different worlds awesome

But perhaps the last word belongs to the girl who voiced what we may all have occasionally felt: "I like it better than real life because I hate people and their germy whiny little lives.”

\section{Conclusion}

A significant issue for SNS designers and academics across several disciplines is the paucity of research in this sector of media practice, considering the ubiquity of SNS use amongst teenagers and adults. Psychiatrists are now considering social network use as a standard tool in adolescent psychiatric evaluation (King and Delfabbro, 2014). The persuasive design mechanisms that drive behaviour on these sites should surely be a standard interdisciplinary study in media practice, linking psychology, technology and design. More research is clearly needed in this area. 
In behavioural terms, the early days of the internet were characterised by users playing with new identities, where, in the words of the famous cartoon, 'Nobody knows you're a dog' (Steiner, 1993). Social networks, and in particular Facebook, changed that. Many who were concerned that the internet was unregulated even by common societal norms welcomed the change. Parents have come to see "friending” their children on Facebook as an opportunity to provide a supportive, regulatory hand at an important stage of development. Its privacy settings create an illusion of safety, even while it is obvious that sharing with hundreds of friends is not private.

However, this research shows that social networks, in particular Facebook, can create a stifling environment where young people are locked into restricting identities, and surrounded by people trying to create the same image. The online personas are sometimes criticised by adults for their apparent frivolity and sameness, though this research shows that they conceal as much as they reveal, due to pressures to conform that come with inwardlooking social circles. Though Formspring and Ask do not demand the same time-consuming creation of "Brand You", they produce the same negative experiences and fewer positive experiences.

Instead of the internet allowing young people to try their wings, safely exploring other worlds and ways of living, joining inward-facing social networks based on offline contacts may lock them down more firmly to a narrow, mentally confining “village life”. Notwithstanding our idealisation of the "close-knit community", social networks that allow a more outward-facing “city-dweller” experience, such as Twitter, are more interesting and create fewer negative experiences. These findings should help media educators and practitioners create or tweak SNS to produce online environments that promote good mental health and minimise restriction of young people's developing identities. 


\section{Acknowledgements}

I would like to thank Dr Stephen Brindle for his assistance with the statistical work, and Dr Andrew Hobbs for his assistance with the survey.

\section{Biography note}

Amy Binns worked as a journalist for ten years before moving into academia. She teaches writing, photojournalism and digital skills. Her research focuses on difficult behaviour online, particularly as it affects media organisations.

\section{References}

Aiken, M.P, and McMahon, C. 2014. A primer on research in mediated environments: Reflections on cybermethodology Social Sciences Research Network July 5 http://ssrn.com/abstract $=2462700$

Binns, Amy. 2012. “Don’t Feed the Trolls: managing troublemakers in magazines’ online communities.” Journalism Practice 6 (4): 547-562 doi: 10.1080/17512786.2011.648988

Binns, Amy. 2013. “Facebook’s Ugly Sisters: Anonymity and abuse on Formspring and Ask.fm” Media Education Research Journal 4 (1): 27-42.

Basch, D. 2012. Some Fresh Twitter Stats. Available at: http://diegobasch.com/some-freshtwitter-stats-as-of-july-2012 Access date 4 July 2013.

Baumgartner, MP. 1991. The Moral Order of a Suburb New York: Oxford University Press. 
Chou, HG, and Edge, N. 2012. “They are Happier and Having Better Lives than I am” Cyberpsychology, Behavior, and Social Networking. 15(2): 117-121. doi:10.1089/cyber.2011.0324.

Cyr, D, and Bonanni, C. 2005. “Gender and website design in e-business” International Journal of Electronic Business 3 (6): 556-582

Durrant, A, et al. 2011.The secret life of teens: online versus offline photographic displays at home” Visual Studies, 26 (2): 113-124 doi:10.1080/1472586X.2011.571887

Fairbrother, GP. 2007. “Quantative and Qualitative Approaches to Education”. In Comparative Education Research, edited by Bray, M, Adamson, B, and Mason, M. 39-62. London: Springer.

Fogg, BJ, and Jizawa, D. 2008. “Online Persuasion in Facebook and Mixi: A Cross-Cultural Comparison” Lecture Notes in Computer Science 5033: 35-46 doi 10.1007/978-3-540-685043_4

Glendinning, A, et al. 2003. "Rural communities and well-being: a good place to grow up?” Sociological Review. 51(1) 129-156. doi: 10.1111/1467-954X.00411

Haugen,MS, and Villa,M. 2006. “Big Brother in rural societies: Youths’ discourses on gossip” Norwegian Journal of Geography 60: 174-178 doi: 10.1080/00291950600889947

Himelboim I, McCreery, S, Smith, M. 2013. “Birds of a Feather Tweet Together: Integrating Network and Content Analyses to Examine Cross-Ideology Exposure on Twitter" Journal of Computer-Mediated Communication, 18 (2): 40-60 doi: 10.1111/jcc4.12001

Hovarth, Jeff. 2011. "Persuasive Design: It’s not just about selling stuff” Lecture Notes in Computer Science 6770: 567-574 doi 10.1007/978-3-642-21708-1_63 
Huberman, BA, Romero, DM, Wu, F. 2009. “Social networks that matter: Twitter under the micro-scope” First Monday 14(1) doi http://dx.doi.org/10.5210\%2Ffm.v14i1.2317

Hughes, DJ, Rowe, M, Batey, M and Lee, A. 2012. “A tale of two sites: Twitter vs. Facebook and the personality predictors of social media usage” Computers in Human Behavior 28(2) 561-569. doi http://dx.doi.org/10.1016/j.chb.2011.11.001

Kelion, L. 2013. “Censoring Facebook: Social network's violent video dilemma”, BBC News, 10 May. http://www.bbc.co.uk/news/technology-22464290, access date 10 July 2013.

Kim, H, and Fesenmajer, D. 2008. "Persuasive Design of Destination Web Sites: An Analysis of First Impression” Journal of Travel Research 47 (1): 3-13 doi:

$10.1177 / 0047287507312405$

King, Daniel L, and Delfabbro, Paul H. 2014. “My Facebook family: Should adolescent psychiatric evaluation include information about online social networks?” Australian and New Zealand Journal of Psychiatry Published online before print June 25, 2014, doi: $10.1177 / 0004867414542031$

Kirkpatrick, D. 2010. The Facebook Effect: The Inside Story of the Company That is Connecting the World, Simon \& Schuster: New York p198

Kramer, Adam D.I., Guillory, Jamie E., Hancock, Jeffrey, T. 2014. “Experimental evidence of massive-scale emotional contagion through social networks” Proceedings of the National Academy of Sciences of the United States of America 111 (24) 8788-8790 doi: 10.1073/pnas.1320040111 
Kwak, H, et al. 2010. "What is Twitter, a social network or a news media?”, Proceedings of the 19th international conference on World wide web: 591-600.

Lehto, T, and Oinas-Kukkonen, H. 2011. "Persuasive Features in Web-Based Alcohol and Smoking Interventions: A Systematic Review of the Literature” Journal of Medical Internet Research 13(3): e46 doi:10.2196/jmir.1559

Livingstone, S. 2008. “Taking risky opportunities in youthful content creation: teenagers' use of social networking sites for intimacy, privacy and self-expression”, New Media \& Society 10 (3): 393-411 doi: 10.1177/1461444808089415

Marichal, Jose. 2012. Facebook Democracy. Farnham: Ashgate.

Mary M et al. 2013. Teens, Social Media, and Privacy, Pew Research Center.

Matthews, Dylan. 2014. “Facebook tried to manipulate users’ emotions” Vox.com, 30 June http://www.vox.com/2014/6/30/5856938/the-facebook-study-wasnt-just-creepy-it-was-bad$\underline{\text { research }}$

McCreery, MP et al. 2013. “A sense of self: The role of presence in virtual environments” Computers in Human Behaviour 29 (4): 1635-1640. doi: 10.1016/j.chb.2013.02.002

Moore, M, Nakano, T, Enomoto, A, Suda, T. 2012. “Anonymity and roles associated with aggressive posts in an online forum” Computers in Human Behaviour 28 (3): 861-867 doi 10.1016/j.chb.2011.12.005 
O’Hear, S. 2012. “Ask.fm claims it’s overtaken formspring” Techcrunch.com, 27 June, http://techcrunch.com/2012/06/27/ask-fm-claims-its-overtaken-qa-giant-formspring-whatsgoing-on-here/

O’Keeffe, GS and Clarke-Pearson, K. 2011. “The impact of social media on children, adolescents and families” Pediatrics: Official Journal of the American Academy of Pediatrics, 127 (4): 800-804 doi: 10.1542/peds.2011-0054

Reich, SM. 2010. “Adolescents’ Sense of Community on Myspace and Facebook: A MixedMethods Approach” Journal of Community Psychology 38 (6) 688-705 doi: 10.1002/jcop.20389

Simmons, R. 2011. Odd Girl Out $2^{\text {nd }}$ ed. Houghton Mifflin Harcourt, p133.

Steiner, P. 1993. “Nobody knows you're a dog” The New Yorker, 5 July.

Suler, John. 2004. “The Online Disinhibition Effect” CyberPsychology \& Behavior 7(3): 321-326 doi:10.1089/1094931041291295

Sunstein, S, and Thaler, R. 2008. Nudge: Improving decisions about health, wealth and happiness Penguin Books

Sutcliffe, A. 2001. "Heuristic Evaluation of Website Attractiveness and Usability” Lecture Notes in Computer Science 2220: 183-198 doi 10.1007/3-540-45522-1_11

Valkenburg, P, et al. 2005. “Adolescents’ identity experiments on the internet” New Media and Society 7 (3): 383-402 doi: 10.1177/1461444805052282 
Valkenburg, P, and Peter, J. 2009. “Social Consequences of the Internet for Adolescents:A

Decade of Research” Current Directions in Psychological Science. 18(1) 1-5 doi:

10.1111/j.1467-8721.2009.01595.x

Waldman, Katy. 2014. “Facebook’s Unethical Experiment” Slate.com 28 June

http://www.slate.com/articles/health_and_science/science/2014/06/facebook_unethical_exper iment_it_made_news_feeds_happier_or_sadder_to_manipulate.html

Waters, S, and Ackerman, J. 2011. “Exploring Privacy Management on Facebook:

Motivations and Perceived Consequences of Voluntary Disclosure” Journal of Computer

Mediated Communication 17 (1): 101-115 doi: 10.1111/j.1083-6101.2011.01559.x

Wessels, B. 2012.” Identification and the practices of identity and privacy in everyday digital communication” New Media \& Society 14(8): 1251-1268 doi: 10.1177/1461444812450679

Wimmer, RD, and Dominick, JR. 2011. Mass Media Research Wadsworth, 119-122.

\section{Appendix 1: Full Likert-type scale results}

For question on girls' experiences on Facebook.

\begin{tabular}{|l|l|l|l|l|l|l|}
\hline & $\begin{array}{l}\text { Strongly } \\
\text { disagree }\end{array}$ & Disagree & $\begin{array}{l}\text { Neither } \\
\text { agree nor } \\
\text { disagree }\end{array}$ & Agree & $\begin{array}{l}\text { Strongly } \\
\text { agree }\end{array}$ & $\begin{array}{l}\text { Response } \\
\text { count }\end{array}$ \\
\hline Upsetting & 24.2 & 42.1 & 24.5 & 8.8 & 0.4 & 273 \\
\hline Frightening & 38.8 & 40.7 & 16.5 & 3.7 & 0.4 & 273 \\
\hline Embarrassing & 14.6 & 33.2 & 35.8 & 14.6 & 1.8 & 274 \\
\hline $\begin{array}{l}\text { Feeling } \\
\text { left out }\end{array}$ & 23.2 & 36.4 & 25.7 & 14.3 & 0.4 & 272 \\
\hline Fun & 1.8 & 2.9 & 18.6 & 52.9 & 23.7 & 274 \\
\hline Interesting & 3.3 & 4.7 & 20.7 & 53.5 & 17.8 & 275 \\
\hline $\begin{array}{l}\text { Confidence } \\
\text { Building }\end{array}$ & 4 & 15 & 46 & 29.6 & 5.5 & 274 \\
\hline Friendly & 1.8 & 2.9 & 22.1 & 54.3 & 18.8 & 276 \\
\hline
\end{tabular}

For question on girls’ experiences on Twitter. 


\begin{tabular}{|l|l|l|l|l|l|l|}
\hline & $\begin{array}{l}\text { Strongly } \\
\text { disagree }\end{array}$ & Disagree & $\begin{array}{l}\text { Neither } \\
\text { agree nor } \\
\text { disagree }\end{array}$ & Agree & $\begin{array}{l}\text { Strongly } \\
\text { agree }\end{array}$ & $\begin{array}{l}\text { Response } \\
\text { count }\end{array}$ \\
\hline Upsetting & 43.1 & 42 & 13.3 & 1.7 & 0 & 181 \\
\hline Frightening & 56.4 & 31.8 & 11.2 & 0.6 & 0 & 179 \\
\hline Embarrassing & 37.2 & 40.6 & 19.4 & 2.8 & 0 & 180 \\
\hline Feeling left out & 40.2 & 37.4 & 19 & 3.4 & 0 & 179 \\
\hline Fun & 1.1 & 1.6 & 18.6 & 51.4 & 27.3 & 183 \\
\hline Interesting & 0 & 3.3 & 13.3 & 56.9 & 26.5 & 181 \\
\hline $\begin{array}{l}\text { Confidence } \\
\text { Building }\end{array}$ & 4.4 & 12.7 & 46.4 & 28.2 & 8.3 & 181 \\
\hline Friendly & 0.5 & 3.8 & 14.2 & 56.8 & 24.6 & 183 \\
\hline
\end{tabular}


For question on girls’ experiences on Formspring/Ask.

\begin{tabular}{|l|l|l|l|l|l|l|}
\hline & $\begin{array}{l}\text { Strongly } \\
\text { disagree }\end{array}$ & Disagree & $\begin{array}{l}\text { Neither } \\
\text { agree nor } \\
\text { disagree }\end{array}$ & Agree & $\begin{array}{l}\text { Strongly } \\
\text { agree }\end{array}$ & $\begin{array}{l}\text { Response } \\
\text { count }\end{array}$ \\
\hline Upsetting & 21.7 & 29.7 & 29.7 & 13.8 & 5.1 & 138 \\
\hline Frightening & 31.4 & 37.9 & 25 & 5.7 & 0 & 140 \\
\hline Embarrassing & 15.1 & 36 & 30.2 & 17.3 & 1.4 & 139 \\
\hline Feeling left out & 28.8 & 34.8 & 20 & 9 & 0 & 138 \\
\hline Fun & 5.8 & 5.8 & 30.2 & 46.8 & 11.5 & 139 \\
\hline Interesting & 4.3 & 5.7 & 18.4 & 51.8 & 19.9 & 141 \\
\hline $\begin{array}{l}\text { Confidence } \\
\text { Building }\end{array}$ & 12.9 & 26.4 & 42.9 & 16.4 & 1.4 & 140 \\
\hline Friendly & 6.4 & 17.9 & 40.7 & 32.1 & 2.9 & 140 \\
\hline
\end{tabular}

\section{Appendix 2: Usage of platforms by age}

\begin{tabular}{|l|l|l|l|l|}
\hline Age & Total & Facebook & Twitter & Ask/Formspring \\
\hline 13 & $81(23.7 \%)$ & $62(77.5 \%)$ & $39(48.8 \%)$ & $33(40.7 \%)$ \\
\hline 14 & $116(33.9 \%)$ & $89(80.2 \%)$ & $62(55.9 \%)$ & $45(38.8 \%)$ \\
\hline 15 & $123(35.9 \%)$ & $110(96.5 \%)$ & $73(62.9 \%)$ & $56(45.5 \%)$ \\
\hline 16 & $22(6.4 \%)$ & $18(90 \%)$ & $14(70 \%)$ & $12(54.5 \%)$ \\
\hline
\end{tabular}

\section{Appendix 3: Multiple site use}

Of 342 girls surveyed, the following numbers used multiple sites:

Using Facebook and Twitter $=180$ (52.6\%)

Using Facebook and Twitter but not Ask/Formspring = 68 (19.9\%)

Using Facebook and Ask/Formspring = $131(38.3 \%)$

Using Facebook and ask/Formspring but not Twitter $=19$ (5.6\%)

Using Twitter and Ask/Formspring = 112 (32.7\%)

Using Twitter and Ask/Formspring but not Facebook $=0$

Using all three sites $=112(32.7 \%)$ 


\begin{tabular}{|c|c|c|c|c|c|}
\hline & Total Nos & Mean Rank & Chi-Sq & D of $F$ & Sig \\
\hline Frightening: & 107 & $\begin{array}{lr}\text { Facebook: } & 2.10 \\
\text { Formspring/Ask: } & 2.22 \\
\text { Twitter: } & 1.67\end{array}$ & 32.033 & 2 & p 0.000 \\
\hline Embarrassing & 107 & $\begin{array}{lr}\text { Facebook: } & 2.27 \\
\text { Formspring/Ask: } & 2.22 \\
\text { Twitter: } & 1.49\end{array}$ & 60.698 & 2 & p 0.000 \\
\hline Upsetting & 107 & $\begin{array}{lc}\text { Facebook: } & 2.07 \\
\text { Formspring/Ask: } & 2.33 \\
\text { Twitter: } & 1.60\end{array}$ & 48.144 & 2 & p 0.000 \\
\hline $\begin{array}{l}\text { Feeling Left } \\
\text { Out }\end{array}$ & 104 & $\begin{array}{lr}\text { Facebook: } & 2.35 \\
\text { Formspring/Ask: } & 1.99 \\
\text { Twitter: } & 1.66\end{array}$ & 39.561 & 2 & p 0.000 \\
\hline
\end{tabular}


Table 2: Wilcoxon Signed-Rank test for pairwise comparisons of social networking sites by negative experiences

\begin{tabular}{|l|l|l|l|}
\hline & \multicolumn{2}{|l|}{ Adj. Significance } \\
\hline Frightening & Facebook - F/Ask: p 1.000 & Facebook - Twitter: p. 0.005 & F/Ask - Twitter: p. 0.000 \\
\hline Embarrassing & Facebook - F/Ask: p 1.000 & Facebook - Twitter: p. 0.000 & F/Ask - Twitter: p. 0.000 \\
\hline Upsetting & Facebook - F/Ask: p 0.167 & Facebook - Twitter: p. 0.002 & F/Ask - Twitter: p. 0.000 \\
\hline $\begin{array}{l}\text { Feeling Left } \\
\text { Out }\end{array}$ & Facebook - F/Ask: p 0.031 & Facebook - Twitter: p. 0.000 & F/Ask - Twitter: p. 0.055 \\
\hline
\end{tabular}




\begin{tabular}{|c|c|c|c|c|c|}
\hline & $\begin{array}{l}\text { Total } \\
\text { Nos }\end{array}$ & Mean Rank & Chi-Sq & $\mathrm{D}$ of $\mathrm{F}$ & Sig \\
\hline Fun: & 107 & $\begin{array}{lr}\text { Facebook: } & 2.05 \\
\text { Formspring/Ask: } & 1.69 \\
\text { Twitter: } & 2.27\end{array}$ & 29.624 & 2 & p 0.000 \\
\hline Friendly & 111 & $\begin{array}{lr}\text { Facebook: } & 2.12 \\
\text { Formspring/Ask: } & 1.46 \\
\text { Twitter: } & 2.42\end{array}$ & 79.171 & 2 & p 0.000 \\
\hline Interesting & 108 & $\begin{array}{lr}\text { Facebook: } & 1.94 \\
\text { Formspring/Ask: } & 1.90 \\
\text { Twitter: } & 2.42\end{array}$ & 18.229 & 2 & p 0.000 \\
\hline $\begin{array}{l}\text { Confidence } \\
\text { Building }\end{array}$ & 107 & $\begin{array}{lr}\text { Facebook: } & 2.13 \\
\text { Formspring/Ask: } & 1.61 \\
\text { Twitter: } & 2.26\end{array}$ & 35.636 & 2 & p 0.000 \\
\hline
\end{tabular}


Table 4: Wilcoxon Signed-Rank test for pairwise comparisons of social networking sites by positive experiences

\begin{tabular}{|l|l|l|l|}
\hline & \multicolumn{2}{|l|}{ Adj. Significance } & F/Ask - Twitter: p. 0.000 \\
\hline Fun & Facebook - F/Ask: p 0.024 & Facebook - Twitter: p. 0.307 & F/Ask - Twitter: p. 0.000 \\
\hline Friendly & Facebook - F/Ask: p 0.000 & Facebook - Twitter: p. 0.085 & F/ \\
\hline Interesting & Facebook - F/Ask: p 1.000 & Facebook - Twitter: p. 0.006 & F/Ask - Twitter: p. 0.023 \\
\hline $\begin{array}{l}\text { Confidence } \\
\text { building }\end{array}$ & Facebook - F/Ask: p 0.001 & Facebook - Twitter: p. 1.000 & F/Ask - Twitter: p. 0.000 \\
\hline
\end{tabular}


Table 5: Comparison with Valkenburg's results

\begin{tabular}{|l|l|l|l|l|l|}
\hline & Valkenburg & $\begin{array}{l}\text { All platforms } \\
(\mathrm{n}=295)\end{array}$ & $\begin{array}{l}\text { Facebook } \\
(\mathrm{n}=271)\end{array}$ & $\begin{array}{l}\text { Twitter } \\
(\mathrm{n}=175)\end{array}$ & $\begin{array}{l}\text { Formspring } \\
\text { /Ask (n=124) }\end{array}$ \\
\hline Older & 49.8 & - & - & - & - \\
\hline More macho/tougher & 2.9 & 9.8 & 3.7 & 9.1 & 12.1 \\
\hline More beautiful/attractive & 6.6 & 7.5 & 5.9 & 4 & 8.1 \\
\hline More flirtatious & 13.2 & 12.9 & 12.2 & 10.3 & 14.5 \\
\hline More confident & - & 42.7 & 31.4 & 52 & 44.4 \\
\hline
\end{tabular}


Table 6: Attributes missing from the "online you"

\begin{tabular}{|l|l|}
\hline My hopes and fears & $62.2 \%$ \\
\hline My real feelings about myself & $60.4 \%$ \\
\hline My ambitions & $54.3 \%$ \\
\hline My real feelings about my family & $45.1 \%$ \\
\hline My real feelings about my friends & $34.8 \%$ \\
\hline
\end{tabular}

